\title{
Analysis of Heavy Metal Fraction Content in Sewage Sludge from Selected Wastewater Treatment Plants
}

\author{
Ada Wojciula ${ }^{1 *}$, Dariusz Boruszko', Gabriela Pajewska² \\ 1 Białystok University of Technology, Faculty of Civil Engineering and Environmental Sciences, \\ Department of Technology in Environmental Engineering, ul. Wiejska 45E, 15-351 Białystok, Poland \\ 2 A graduate of the Białystok University of Technology, ul. Wiejska 45E, 15-351 Białystok, Poland \\ * Corresponding author's e-mail: ada.wojciula@gmail.com
}

\begin{abstract}
Assessment of the assimilability of elements contained in sewage sludge can only be carried out if their fractions, by means of which the chemical form of the element can be identified, are determined. The total content of heavy metals only makes it possible to determine whether the sludge meets the legal requirements and can be used, inter alia, for reclamation, in agriculture or for the adaptation of land to specific needs that result from waste management plans. Therefore, when planning the agricultural use of sewage sludge, attention should be paid above all to the heavy metal fractions contained in it. This is due to the fact that plants do not assimilate every form of element to the same extent. The research and analysis carried out indicate that the metals were most closely related to fractions IV and III, for example they formed connections with silicates, as well as sulphides and organic matter. The metal forms available to plants occupied a small percentage of the total heavy metal content. It was noted that with the metastable fraction of lead increased along with population equivalent. Furthermore, the population equivalent value did not affect the distribution of individual heavy metal fractions in the sludge.
\end{abstract}

Keywords: sewage sludge, heavy metals, heavy metal fractions

\section{INTRODUCTION}

According to the Central Statistical Office, the number of municipal wastewater treatment plants in Poland has increased by 125 over the last 10 years. In 2009, there were 3,153 wastewater treatment plants, while in 2019, there were 3,278 plants. This is related to the growing population served by wastewater treatment plants. The population using wastewater treatment plants in relation to the total population was $64.2 \%$ in 2009 , $71.5 \%$ in 2014 and $74.5 \%$ in 2019 . The increase in the amount of wastewater treated and the increasing proportion of people using it contribute to the formation of an increasing amount of sewage sludge. In 2009, 563,115 tonnes of sewage sludge was generated, and in 2019 this amount was more than 10,000 tonnes higher [www.bdl. stat.gov.pl]. Table 1 shows the percentage use of sewage sludge in relation to the total amount produced in a given year.
According to the data in Table 1, by far the most sludge is used in agriculture. These quantities have been at a similar level for 10 years. At this point, it should be stressed that organic pollutants in the form of aliphatic and aromatic hydrocarbons [Ofman and Skoczko 2018, Matejczyk et al. 2020] and inorganic pollutants may be present in sewage sludge, among which mainly metallic elements, including heavy metals, are predominant. In addition, the amounts of these pollutants may depend not only on the chemical characteristics of wastewater flowing into the treatment plant, but also on seasonal changes in the composition of raw wastewater [Skoczko et al. 2017]. Nevertheless, in light of the Polish legal regulations, the content of heavy metals in sewage sludge is of key importance, because, among other things, on this basis an analysis of the possibility of their further use is made [Dlugosz and Gawdzik, 2014]. However, taking into account the agricultural use of sewage sludge, the knowledge 
of the overall content of a given element provides the information about its amount introduced into the environment. From the point of view of the further development of plants, it is important to determine the form in which the element occurs [Wikarek-Paluch et al., 2016].

It is therefore important to know the content of elements in the sludge by fractions, which makes it possible to determine the mobility of the elements. Such an action reduces the occurrence of the toxic effect caused by the excess of individual elements in the soil and, consequently, the negative impact on plants [Bozkurt et al. 2006; Dąbrowska and Nowak, 2014]. Additionally, determining the mobility of selected elements is important due to their further migration in the environment, also to animal or human tissues [Boruszko, 2013, Amir et al. 2005]. Appropriate agricultural practice allows avoiding unwanted effects on breeding and harvesting [Dąbrowska and Nowak, 2014; Ignatowicz et al., 2011].

The most accessible form for plants is the mobile fraction, also known as exchangeablecarbonate, where the elements are bound to carbonates. This form is soluble in acids. Therefore, in a more acidic environment, more heavy metals from this fraction can be released and then transferred to plants. Fraction II, referred to as unstable or reducible, contains the metals bound to manganese and iron oxides [Gawdzik, 2010; Boruszko, 2013]. The mobility of the elements present in this fraction depends on the changes in the oxidation-reduction potential. Anaerobic conditions cause the metal compounds with $\mathrm{Mn}$ or $\mathrm{Fe}$ oxides to dismutate, resulting in the release of the element. Fraction III, referred to as metastable or oxidisable, is an organometallic and sulphide form, which means that metals are bound to sulphides and organic matter. The decomposition of sludge organic matter, under both aerobic and anaerobic conditions, may result in the release of metals. The microorganisms in contact with sewage sludge play an important role in this case. The fraction IV called residual or stable contains the metals which are bound to silicates. In this fraction, the elements are completely immobilised under natural conditions [Gadd and others, 2014; Wasilkowski and Mrozik, 2016; Żelezik and Gawdzik, 2015]. The mobility of metals in the soil environment may change dynamically, depending on the existing physical, chemical or biological conditions [Wasilkowski and Mrozik, 2016].

Taking into account the potential benefits from the agricultural use of sewage sludge, the aim of the study was to determine the content of $\mathrm{Cu}, \mathrm{Zn}, \mathrm{Ni}, \mathrm{Cd}$ and $\mathrm{Pb}$ present in the total forms and fractions of sludge from wastewater treatment plants of population equivalent from about 2000 to more than 100000 and to indicate the statistically significant differences between the content of individual forms of the studied elements.

\section{MATERIALS AND METHODS}

The sludge samples were collected from the wastewater treatment plants located in the Podlaskie Voivodeship. The size of individual facilities was selected in such a way that each of the selected treatment plants represented one group of the size of such facilities specified in the Regulation of the Minister of Maritime Economy and

Table 1. Use of sewage sludge in relation to the total quantity produced in years 2009-2019 [www.bdl.stat.gov.pl.]

\begin{tabular}{|c|c|c|c|c|}
\hline \multirow{2}{*}{ Year } & \multicolumn{3}{|c|}{ Percentage [\%] of sewage sludge utilisation methods in Poland } \\
\cline { 2 - 5 } & agriculture & $\begin{array}{c}\text { land reclamation, } \\
\text { including land for } \\
\text { agricultural purposes }\end{array}$ & $\begin{array}{l}\text { growing plants intended } \\
\text { for compost production }\end{array}$ & deposited \\
\hline 2009 & 21.86 & 13.82 & 4.18 & 14.49 \\
\hline 2010 & 20.76 & 10.31 & 5.87 & 11.19 \\
\hline 2011 & 22.39 & 10.48 & 5.97 & 9.91 \\
\hline 2012 & 21.57 & 9.43 & 6.25 & 5.77 \\
\hline 2013 & 19.52 & 5.44 & 6.03 & 5.81 \\
\hline 2014 & 19.29 & 3.95 & 8.33 & 7.12 \\
\hline 2015 & 18.93 & 3.37 & 8.29 & 3.64 \\
\hline 2016 & 20.42 & 3.53 & 5.6 & 2.61 \\
\hline 2017 & 18.57 & 3.37 & 4.43 & 1.82 \\
\hline 2018 & 20.29 & 2.99 & 4.32 & 1.63 \\
\hline 2019 & 21.59 & 2.65 & 5.33 & \\
\hline
\end{tabular}


Inland Navigation of 12 July 2019. The studied sewage sludge was collected after the dewatering process, before its stabilisation. The aim of this approach was to homogenise the analysed sludge in terms of its technological preparation for further treatment. Such an approach enabled a more accurate comparison of the content of studied elements in individual sludge fractions.

The samples of sewage sludge were dried to constant weight at $105^{\circ} \mathrm{C}$ before the analysis of the heavy metal content. Then, the analysis of the $\mathrm{Cu}$, $\mathrm{Zn}, \mathrm{Ni}, \mathrm{Cd}$ and $\mathrm{Pb}$ content was performed using the shortened BCR sequential extraction method [Łapiński et al. 2019]. An important advantage of the shortened BCR method is the shorter time of sample preparation for analysis compared to the classical method, which is achieved by sample mixing using ultrasound generated by the sonifiers. Therefore, in the methodology, it was established that the probe amplitude would be $70 \%$ at $15 \mathrm{~W}$ and there would be 15 -second breaks after every 15 seconds of operation. The depth of immersion of the probe in the solution was $4 \mathrm{~cm}$, measured from the surface of the solution.

For BCR extraction and for the determination of the total forms of the studied elements $1 \mathrm{~g}$ of the sample was used. The first fraction was extracted using $40 \mathrm{ml}$ of $0.11 \mathrm{~mol} \cdot \mathrm{dm}^{-3}$ solution $\mathrm{CH}_{3} \mathrm{COOH}$ at extraction time of 7 minutes, the second fraction was extracted using $40 \mathrm{ml}$ of $0.5 \mathrm{~mol} \cdot \mathrm{dm}^{-3}$ solution $\mathrm{NH}_{2} \mathrm{OH}-\mathrm{HCl}$ at extraction time of 10 minutes. Before extraction of the examined heavy metals from the third fraction, the organic matter was oxidized with $10.0 \mathrm{ml} \mathrm{H}_{2} \mathrm{O}_{2}$ at $30 \%$ concentration. The process of organic matter oxidation was carried out on a water bath. After evaporation of $\mathrm{H}_{2} \mathrm{O}_{2}$ from the sample, it was extracted with $50 \mathrm{ml}$ of $1.0 \mathrm{~mol} \cdot \mathrm{dm}^{-3}$ solution $\mathrm{CH}_{3} \mathrm{COONH}_{4}$ at extraction time equal to 4 minutes. However, the samples for determination of the fourth fraction were burnt at $450^{\circ} \mathrm{C}$ and then mineralized in aqua regia, which was prepared with $9.0 \mathrm{~cm}^{3} \mathrm{HCl}$ and $3 \mathrm{~cm}^{3} \mathrm{HNO}_{3}$. Apart from the fractions of individual elements, the content of their total forms in individual sludge samples was also determined. For this purpose, the sludge sample was burned at $450^{\circ} \mathrm{C}$ and then mineralized in a mixture of $\mathrm{HNO}_{3}\left(9 \mathrm{~cm}^{3}\right)$ and $\mathrm{H}_{2} \mathrm{O}_{2}\left(1 \mathrm{~cm}^{3}\right)$ in a microwave digester.

The obtained results of laboratory analyses were statistically processed. In order to verify and indicate the differences between the observed contents of particular elements in sewage sludge.
Such a comparison makes it possible to indicate the smallest significant differences using the analysis of variance [Ofman et al. 2020, StrukSokołowska et. al. 2020]. Therefore, one quality factor was taken into account in the analysis of variance, which was population equivalent. In contrast, the content of individual elements in fractions and total forms were dependent variables. It should be noted that the variables adopted for the analysis must have a normal distribution and homogeneity of variance. Therefore, all variables included in the analysis were characterised by normal distribution according to the SaphiroWilk test and homogeneity of variance according to the Bartlett test, whereas $\alpha=0.05$ was chosen for the level of statistical significance. All statistical calculations were carried out with the use of licensed Statistica software version 13.1, operating on the Windows 10 platform.

\section{RESULTS AND DISSCUSION}

The sludge samples from 5 wastewater treatment plants (WWTP) of different sizes of population equivalent (PE) were analysed. Therefore, they were given the following numbers: WWTP below 2000 PE- 1; WWTP 2000 to 9999 PE- 2; WWTP 10000 to 14999 PE- 3; WWTP 15000 to 99999 PE- 4; WWTP over 100000 PE- 5. The above-mentioned numbering was used in the further description.

The highest amount of total copper (Fig. 1) was found in the sewage sludge from WWTP No. $2(92.85 \mathrm{mg} / \mathrm{kg}$ d.m.). Similar and at the same time the lowest content of this element was found in the sewage sludge from WWTP 1,3 and 4 (about $70 \mathrm{mg} / \mathrm{kg} \mathrm{d.m.).} \mathrm{The} \mathrm{high-}$ est zinc content was observed in WWTP No. $3(220.70 \mathrm{mg} / \mathrm{kg}$ d.m. $)$. Although the treatment plants differ significantly in terms of PE, the zinc content of each sewage sludge was similar. The highest amount of nickel in the sewage sludge $(21.81 \mathrm{mg} / \mathrm{kg} \mathrm{d.m}$.) was observed for WWTP No. 4 , but in this case, also other samples showed similar metal content (17.38-18.99 mg/kg d.m.). The range of cadmium content for all samples was $7.55-9.82 \mathrm{mg} / \mathrm{kg}$ d.m., with $9.82 \mathrm{mg} / \mathrm{kg}$ d.m. being found in sample No. 4. The least amount of lead was found in sewage sludge No. $3(2.49 \mathrm{mg} / \mathrm{kg} \mathrm{d.m}$. $)$ and the most in sewage sludge No. 1 (4.08 mg/kg d.m.). After analysing the content of elements in the sewage sludge for 


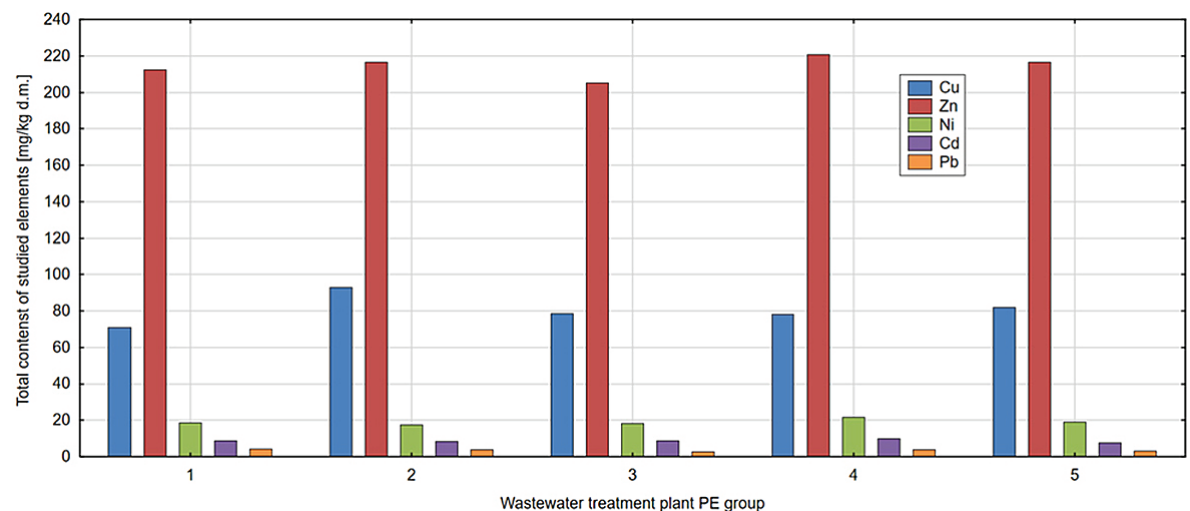

Fig. 1. Total heavy metal content of sludge from studied wastewater treatment plants

all samples, it was found that the sewage sludge meets the requirements of the Ordinance of the Minister of Environment of 6 February 2015 on municipal sewage sludge. Therefore, the sewage sludge from the studied WWTPs can be used in agriculture and for land reclamation for agricultural purposes, provided that the sludge is not applied to the top soil layer $(0-25 \mathrm{~cm})$.

The obtained total contents of the studied elements in the samples of sewage sludge from individual wastewater treatment plants were compared with the use of Tukey's NIR test. The aim of the comparison was to indicate the potential differences in the $\mathrm{Cu}, \mathrm{Zn}, \mathrm{Ni}, \mathrm{Cd}$ and $\mathrm{Pb}$ contents, which could result from the number of WWTPs determined by PE value. According to Tukey's NIR test results, statistically significant differences in the $\mathrm{Cu}$ content were observed in the sludge samples collected from treatment plants 2 and 1 , 3 and 4. In other cases, no statistically significant differences were observed. The $\mathrm{Zn}$ content did not differ statistically significant $(\alpha=0.05)$ between individual sludge samples. On the other hand, the Ni content was statistically significantly different between the sludge samples collected from WWTP 2 and 4. The Cd content showed statistically significant differences only in the case of the samples collected from WWTP 4 and 5, while the $\mathrm{Pb}$ content was statistically significantly different between the samples of sludge collected from WWTP 1 and WWTP 3 and 5, between the sludge from WWTP 2 and 3 and the sludge from WWTP 4 and 5. The occurrence of statistically significant differences in the content of individual elements may result from different chemical characteristics of wastewater flowing into individual facilities [Krupicz and Masłoń, 2016, Vieno et al. 2005].

Copper fraction I, interchangeable-carbonate, was present in the largest quantity in the sample from treatment plant 2 (PE from 2000 to 9999). In the sludge from treatment plants no. 4 and 5, fraction I did not exceed $1 \%$ of total copper content. On the basis of Figure 2, it can be concluded that in the wastewater treatment plant with the lowest PE the opposite relation was found than in the other studied objects. In the first plant, copper in the sludge was mainly associated with

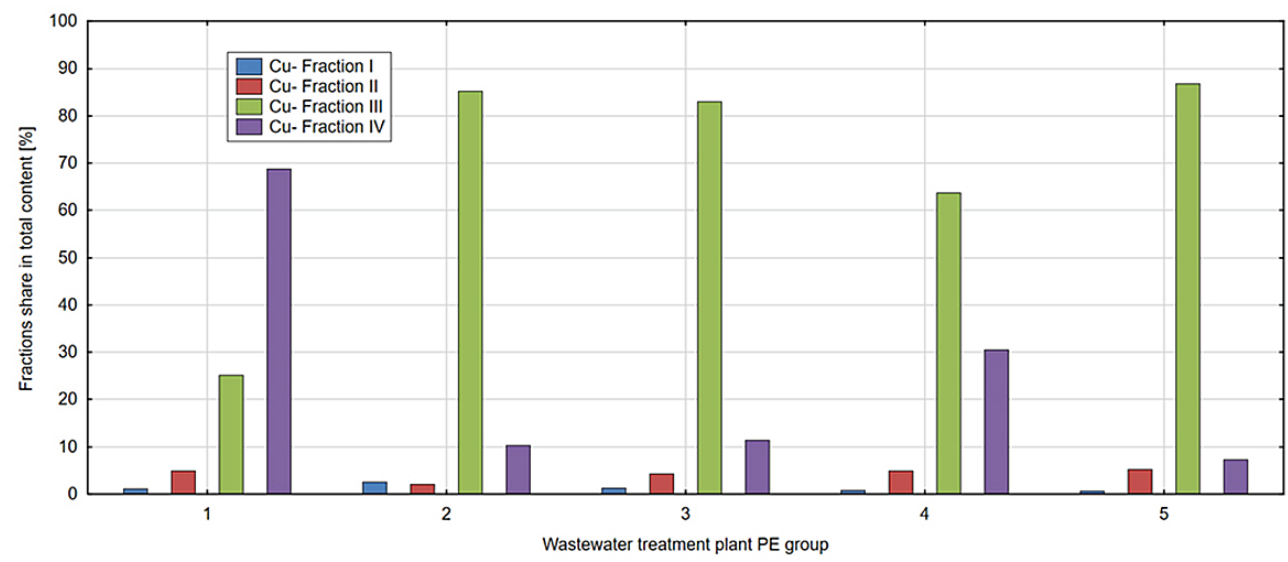

Fig. 2. Percentage content of copper fraction in sewage sludge from studied WWTPs 
silicates (69\%), and in the remaining sludge, this element formed compounds with sulfides and organic matter. Zorpas and others (2008) presented the studies of heavy metal fractions in the sludge from a WWTP located in Greece, Athens. This plant produces about 250 tonnes of sludge from municipal and industrial wastewater per day. For comparison, at the Bialystok WWTP in Podlaskie Voivodeship, 6,855 tonnes of sludge [bdl.stat. gov.pl] are generated annually from both types of wastewater. Therefore, the Greek WWTP generates much more sludge every day. Zorpas and others (2010) presented the copper content of raw sewage before stabilisation. In this case, sludge was strongly associated with fraction III, metastable, in $70 \%$. A very similar result was obtained for WWTP No. 1, and yet the size of the sludge generated, and thus the population served by the plant, differ significantly between the facilities compared. It should be noted that the studied sewage sludge was dehydrated and unstable.

The $\mathrm{Cu}$ content in fraction I was statistically significantly different between the sewage sludge collected from 2 WWTPs and other samples, additionally, statistically significant differences in the content of this element were observed between the $\mathrm{Cu}$ content in sludge from WWTP 3 and the samples collected from WWTP 4 and 5. Similar regularities were observed in fraction II of $\mathrm{Cu}$. For $\mathrm{Cu}$ fractions III and IV, statistically significant differences were observed between the content of this element in WWTP 1 and WWTPs 2,3 and 5 .

Zinc in the sewage sludge from each facility, in the greatest quantity, was present as fraction III or IV. There was a similar relationship as in the case of copper. Zinc in sewage sludge from WWTP No. 1 was most closely related to silicates, and in the remaining objects, to sulphides and organic matter. However, it is worth noting, that the element, as the most mobile fraction (I), constitutes about $15 \%$ of the total content. The exception is object no. 2 , where only $5 \%$ of the zinc bound to carbonates was found in the sludge. Gawdzik (2012) presented the percentage share of metal fractions in the sludge from the WWTP in Ostrowiec Świętokrzyski. It is an object of 88 060 PE. The author presented the highest zinc content as fraction III (57\%) and IV (35\%). The mobile fractions do not exceed even 5\%. According to Figure 2, zinc in the sludge of object 4 was associated in about $30 \%$ with mobile fractions (I and II). Żelezik and Gawdzik (2015) showed in their studies that heavy metals in connections with organic matter and aluminosilicates have the largest share and are the dominant forms. On the basis of Figure 3, similar conclusions can be drawn as those presented by other authors.

The $\mathrm{Zn}$ content of the studied sludge samples in fraction I was statistically significantly different between WWTP 2 and the other studied objects. In fraction II, differences were observed between the samples collected from WWTP 2 and WWTP 1 and 3 and the between samples collected from WWTP 3 and 4. The third Zn fraction was statistically significantly different between the samples from WWTP 1 and the samples collected from WWTP 2, 3 and 5, whereas in fraction IV no statistically significant differences were observed.

As shown in Figure 4, the PE value did not affect the content of individual fractions of nickel in the sludge. Metal was almost always associated with silicates to the greatest extent, but the percentage of this fraction did not differ significantly from that of nickel in the other fractions. Nickel in the exchanger-carbonate fraction was present in each sample in an amount greater than $20 \%$. According to the research conducted by

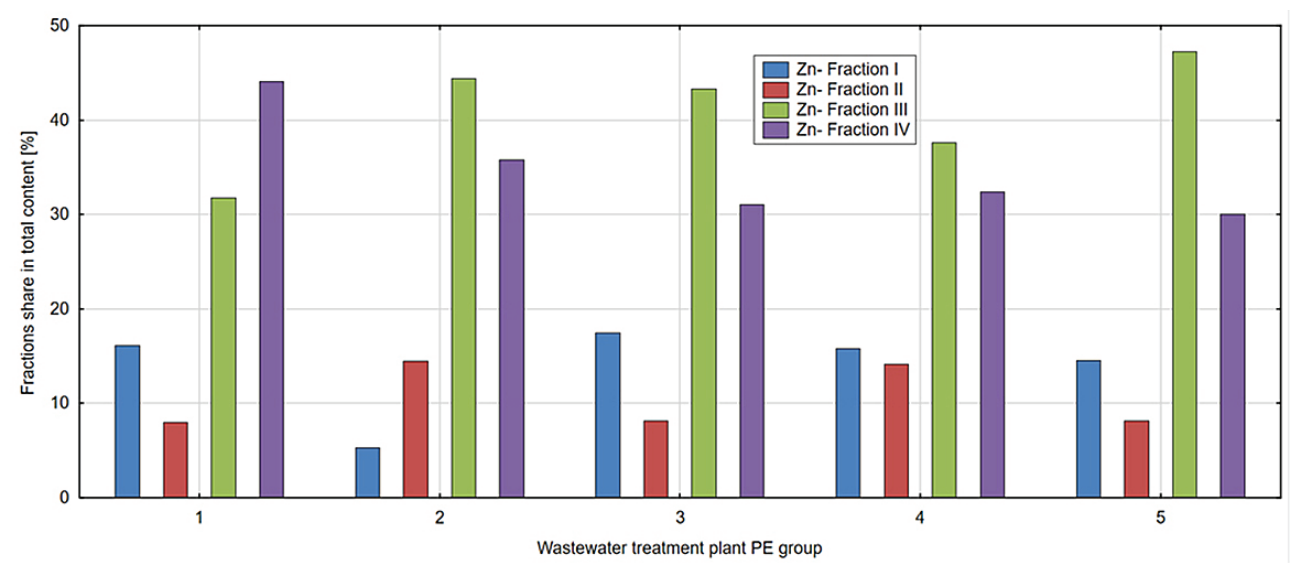

Fig. 3. Percentage content of zinc fraction in sludge from the studied WWTPs 


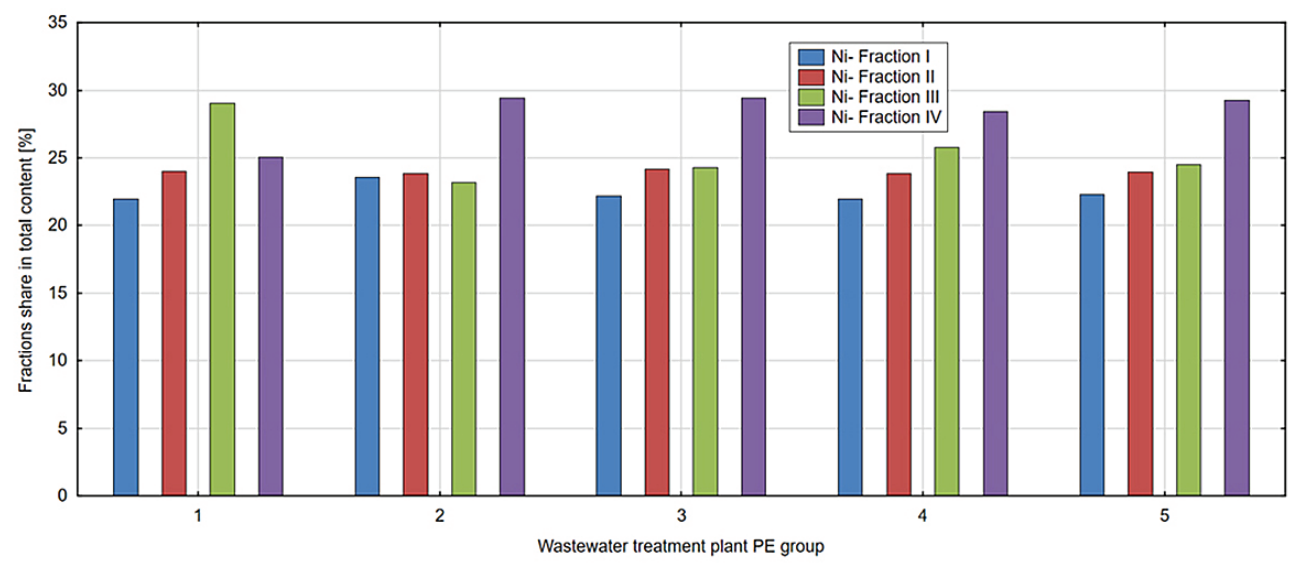

Fig. 4. Percentage content of nickel fraction in sludge from studied WWTPs

Ignatowicz et al. [2011], the sewage sludge from the Sokółka WWTP contained the least nickel associated with silicates (14\%) and the most with organic matter (44\%). It is a facility with a maximum daily capacity of $6708 \mathrm{~m}^{3}$ and PE of 34367 . Therefore, it is necessary to compare the Sokółka sludge to the sludge from the treatment plant no. 4. The relationship is different because in facility no. 4 , nickel as a stable fraction occurred in about $28 \%$, and as an oxidising fraction, it did not exceed 26\%. The mobile fractions (I and II) had quite high share. However, similar results were presented for the sludge from Psyttaleia, a Greek island. The percentage of nickel in individual sludge fractions before stabilisation was relatively even, with a predominance of the reductive or unstable fraction [Zorpas et al., 2010]

In the case of $\mathrm{Ni}$, no statistically significant differences were observed in the content of this element in fractions I and IV. In fraction II, statistically significant differences were observed between the Ni content in the sludge samples from WWTPs
2 and 4. On the other hand, in fraction III of Ni, statistically significant differences were observed in the samples collected from WWTP 1 and WWTPs 2 and 3 as well as in the samples collected from WWTP 4 and samples from WWTPs 2, 3 and 5.

According to Figure 5, in a wastewater treatment plant with the highest number of PE, cadmium was by far the least carbonate related. Taking into account other WWTPs, each fraction was in the range $20-30 \% \mathrm{Cd}$, with a slight advantage of the residual fraction. Lapiński and others (2019) presented the percentage of heavy metals in the dried sewage sludge. According to the authors, cadmium was most closely related to silicates $(51 \%)$ and organic matter $(24 \%)$. The distribution was not as even as in the case of the studies carried out for the selected WWTPs, but the trend of predominance of non-mobile fractions was maintained. Żelezik and Gawdzik (2015) showed a similar relationship, as the mobile fractions of cadmium in sludge did not exceed $20 \%$ and for the others the distribution was similar.

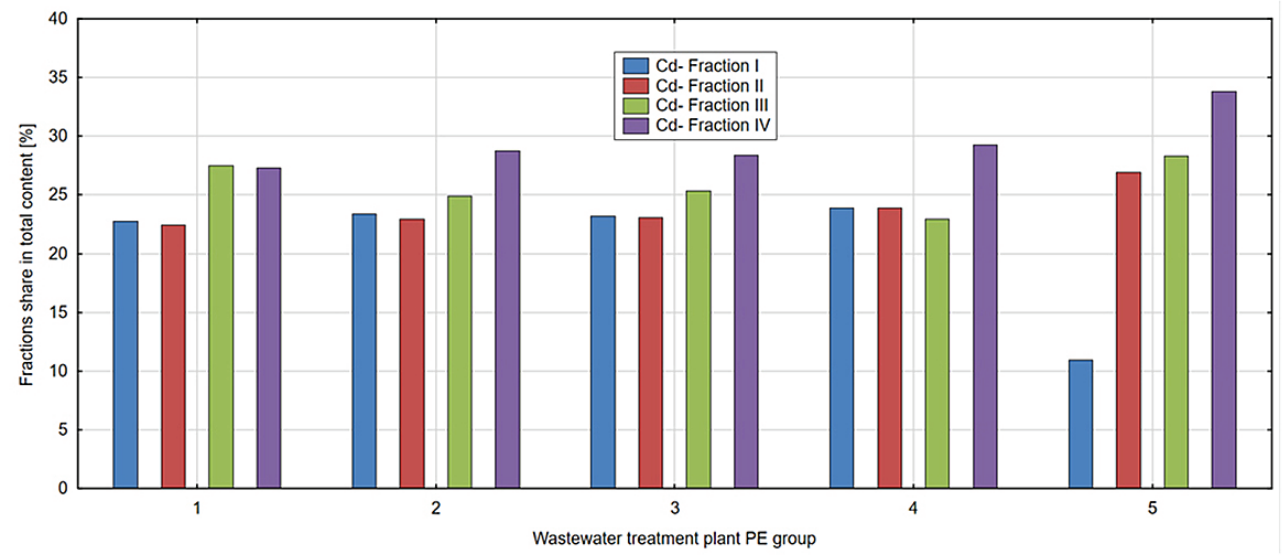

Fig. 5. Percentage content of cadmium fraction in sewage sludge from studied WWTPs 


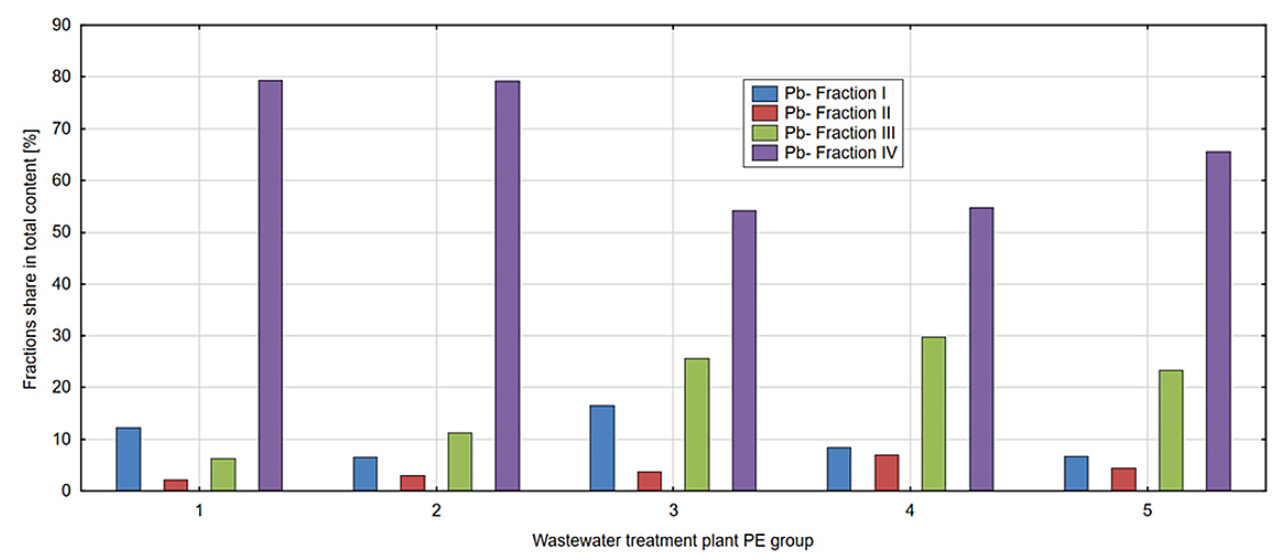

Fig. 6. Percentage content of lead fraction in the sewage sludge from the studied WWTPs

The statistically significant differences in the $\mathrm{Cd}$ content of the first fraction were observed between the samples collected from 5 WWTPs and the rest of the plants studied. In fraction II, only the differences between WWTPs 2 and 4 were observed, whereas in fractions III and IV no statistically significant differences were noted.

In each case analysed, lead was by far the most related to silicates, as shown in Figure 6. An upward trend in the oxidation fraction was observed. The higher the PE value of the plant, the more lead associated with the organic substance. The exception is object no. 5, although despite this, fraction III of the metal constituted more than $20 \%$ of all forms. In each sample, more exchangeable than reducible fraction was found. It is worth noting that fraction I is more mobile, because the movement of metals determines the acidification of the environment, and not the oxidation and reduction conditions, as in the case of fraction II. A very similar relationship was noted for the Daleszyce WWTP, the PE value of which is less than 10000 . Over $95 \%$ of lead was a residual form. Moreover, the metal was more bound to carbonates than to manganese and iron oxides [Kowalik and others, 2020].

The $\mathrm{Pb}$ content in fraction I was statistically significant between WWTP 1 and WWTPs 2 and 5. No statistically significant differences were observed in fractions II and III, while in fraction IV, differences were observed between the samples from WWTP 3 and WWTPs 1 and 2.

\section{CONCLUSIONS}

1. The content of heavy metal fractions in the sewage sludge varied, but by far the most metals were associated with silicates as well as sulphides and organic matter. This means that the elements present in these forms are practically inaccessible to plants under natural conditions.

2. The mobile forms available to plants had a much lower percentage than other fractions. The exceptions were nickel and cadmium, which occurred in similar quantities in each form. Comparing the results to the works presented by other authors, it was found that the metal contents varied, depending on the object under study, and above all on the degree of sludge processing.

3. However, similar relationships have been noted, such as the advantage of faction IV over others. After analysing the results, it was concluded that the PE value did not affect the distribution of individual heavy metal fractions. The exception was lead, in which a tendency for fraction III to increase with PE was noted.

\section{REFERENCES}

1. Amir S., Hafidi M., Marlina G., Revel J. C. 2005. Sequential extraction of heavy metals during composting of sewage sludge. Chemosphere, 59, 801-810.

2. Boruszko D. 2013. Fractionation of Heavy Metals in Sewage Sludge Processed by Low-input Methods. Annual Set The Environment Protection, 15, 1787-1803 (in Polish).

3. Bozkurt M.A., Akdeniz H., Keskin B., Yilmaz I.H. 2006. Possibilities of using sewage sludge as nitrogen fertilizer for maize. Acta Agriculturae Seandinavica Section B-Soil and Plant Science, 56, 143-149.

4. Cheng M., Wu Longhua., Huang Y., Luo Y., Christie P. 2013. Total concentrations of heavy metals and 
occurence of antibiotics In sewage sludges from cities throughout China. Journal of Soils and Sediments, 14(6), DOI: 10.1007/s11368-014-0850-3.

5. Dąbrowska L., Nowak R. 2014. Chemical fractions of heavy metals in sewage sludge and in residue after incineration of sewage sludge. Engineering and Protection of Environment, 17(3), 403-414 (in Polish).

6. Długosz J., Gawdzik J. 2014. The content of heavy metals in sewage sludge conditioned $\mathrm{CaO}$. Archives of Waste Management and Environmental Protection, 16(2), 49-56.

7. Gadd G.M., Bahri-Esfahani J., Li Q., Rhee Y.J., Wei Z., Fomina M., Liang X. 2014. Oxalate production by fungi: significance in geomycology, biodeterioration and bioremediation. Fungal Biol. Rev. 28, 36-55.

8. Gawdzik J. 2012. Mobility of heavy metals in sewage sludge for example wastewater treatment plant. Engineering and Protection of Environment, 15(1), 5-15 (in Polish).

9. Gawdzik J.I. 2010. Speciation of heavy metals in sewage sludge: A case study. Environmental Pollution Control, 32(4), 15-19 (in Polish).

10. Statistics Poland: www.bdl.stat.gov.pl.

11. Gondek K. 2006. Contents of different forms of heavy metals in sewage sludge and composts. Faculty of Agriculture and Economics, University of Agriculture in Krakow. Acta Agrophysica, 8(4), 825-838 (in Polish).

12. Ignatowicz K., Garlicka K., Breńko T. 2011. The influence of sewage sludge composting for content of chosen metals and their fractions. Journal of Ecological Engineering, 25, 231-241 (in Polish).

13. Kowalik R., Gawdzik J., Gawdzik B., Gawdzik A. 2020. Analysis of the mobility of heavy metals In sludge for the sewage treatment plant In Daleszyce. Structure and Environment, 12(2), 85-92.

14. Krupicz A., Masłoń A. 2016. Variability of pollutant loads inflowing to the wastewater treatment plant in Stalowa Wola. Journal of Civil Engineering, Environment and Architecture, vol. XXXIII, 63, 101-114 (in Polish).

15. Łapiński D., Wiater J., Szatyłowicz E. 2019. The Content of Heavy Metals in Waste as an Indicator Determining the Possibilities of Their Agricultural Use. Journal of Ecological Engineering, 20(4), 225-230.

16. Matejczyk M., Ofman P., Dąbrowska K., Świsłocka R., Lewandowski W. 2020. The study of biological activity of transformation products of diclofenac and its interaction with chlorogenic acid, Journal of Environmental Sciences, 91, 128-141.

17. Ofman P., Skoczko I. 2018. PAH removal effectiveness comparison from hydraulic fracturing model wastewater in SBR reactors with granular and flocked activated sludge, Desalination and Water Treatment, 134, 41-51.

18. Ofman P., Struk-Sokołowska J., Skoczko I., Wiater J. 2020. Alterned biodegradation of naphthalene (NAP), acenapthylene (ACY) and acenaphthene $(\mathrm{ACE})$ in an aerobic granular sludge reactor (GSBR), Journal of Hazardous Materials, 383, 1-12.

19. Rajmund A., Bożym M. 2013. An assessment of the contents of heavy metals in sewage sludge from rural area and composts, in the aspect of their natural use. Water-Environment-Rural Areas, 13, 4(44), 103-113 (In Polish).

20. Regulation of the Minister of Environment of 6 February 2015 on municipal sewage sludge (in Polish).

21. Skoczko I., Struk-Sokołowska J., Ofman P. 2017. Sesonal changes in nitrogen, phosphorus, BOD and COD removal in Bystre wastewater treatment plant, Journal of Ecological Engineering, 18(4), 185-191

22. Struk-Sokolowska J., Gwozdziej-Mazur J., Jadwiszczak P., Butarewicz, A.,Ofman, P., Wdowikowski M., Kazmierczak B., 2020, The Quality of Stored Rainwater for Washing Purposes, Water, 12(1), 1- 17

23. Vieno N.M., Tuhkanen T., Kronberg L. 2005. Seasonal Variation in the Occurrence of Pharmaceuticals in Effluents from a Sewage Treatment Plant and in the Recipient Water. Environmental Science and Technology, 39(21), 8220-8226.

24. Wasilkowski D., Mrozik A. 2016. Recultivation of heavy metal-contaminated soils using aided phytostabilization. Advancements of Microbiology, 55(4), 413-423 (In Polish).

25. Wikarek-Paluch E., Rosik-Dulewska C., Karwaczyńska U. 2016. Mobility of Selected Heavy Metals in Municipal Sewage Sludge. Annual Set The Environment Protection, 18, 181-192 (in Polish).

26. Żelezik M., Gawdzik J. 2015. Archives of Waste Management and Environmental Protection. The content of heavy metals species in sewage sludge from wastewater treatment plants in Mniów, 17(1), 119-126.

27. Zorpas A.A., Inglezakis V.J., Loizidou M. 2007. Heavy metals fractionation before, during and after composting of sewage sludge with natural zeolite. Waste Management, 28(11), 2054-2060. 